(10.9\%) of the patients with DAS28 $<2.6$ which were on systemic corticosteroid (CS) treatment regimen.

Conclusions: The presence of active synovitis on PDUS in a significant part of the studied PsA patients (35.9\%) which were considered as being in clinical remission for at least 6 months showed that these kind of patients need to be closely followed-up and adequately treated. The systemic CS treatment does not exclude the presence of disease activity in PsA. Further studies for assessment of the synovitis will establish correct criteria for defining and monitoring the disease activity in PsA.

Disclosure of Interest: None declared

DOI: 10.1136/annrheumdis-2017-eular.6634

\section{FRI0517 QUALITY OF LIFE IN PATIENTS WITH EARLY PSORIATIC ARTHRITIS}

S. Monov, A. Kopchev. Clinic of Rheumatology, Department of Internal Medicine, Medical University, Sofia, Sofia, Bulgaria

Background: Psoriatic arthritis (PsA) is a chronic systemic inflammatory disease. Affecting skin, joints, entheses and dactylitis, its impact on health-related qualityof-life (HRQoL) could be substantial.

Objectives: The aim of this study was to describe HRQoL in newly diagnosed PsA patients taking into account skin involvement, swollen joints, tender enthuses and dactylitis.

Methods: HRQoL was assessed by 8 subscales of the Short-Form 36 (SF-36) questionnaire $(0-100$, higher score represents a better HRQoL). Patients were classified in arthritis subtypes (i.e. mono-, oligo- or polyarthritis) by rheumatologist. Entheses were evaluated using the Leeds Enthesitis Index (LEI) and Maastricht Ankylosing Spondylitis Enthesitis Score (MASES; positive if tender entheses $>1$ ). Psoriasis was evaluated using the Psoriasis Area Severity Index (PASI; mild: 0-7; moderate/severe: $>7$ ) and dactylitis using the Leeds Dactylitis Index (LDI).

Results: 87 patients (48 male, 39 female, mean age 47,6 $\pm 15,3$ ) with PsA (21 had monoarthritis, 49 - oligoarthrit and 17 - polyarthritis) completed the SF-36 were included in the study. Psoriasis was mild in $63(72,41 \%)$ patients and moderate/severe in $12(13,79 \%)$ patiients. At least one digit with dactylitis was present in $10(11,49 \%)$ of the patients. A tender enthesis was present in 39 $(44,83 \%)$ of patients. Mean scores of the subdomains in the SF-36 were similar across the different arthritis groups, with slightly worse scores for polyarthritis compared to mono- and oligoarthritis. However, when stratifying these groups for the presence of a tender enthesis, HRQoL decreased substantially for all groups across all subdomains of the SF-36, with a median difference of 12,9 points. Irrespective of joint involvement, a tender enthesis decreased the mean scores of all subdomains significantly compared to the non-tender enthesis group $(p<0,05)$. Severity of psoriasis and presence of dactylitis did not lead to significantly different SF-36 values compared to those not affected.

Conclusions: Having tender entheses impacts HRQoL severly in both its physical and mental dimensions in incident untreated PsA.

Disclosure of Interest: None declared

DOI: 10.1136/annrheumdis-2017-eular.6603

\section{FRI0518 PRESCRIPTION PATTERNS OF TUMOUR NECROSIS FACTOR INHIBITOR AND USTEKINUMAB IN PSORIATIC ARTHRITIS: A NORDIC POPULATION-BASED COHORT STUDY}

T.S. Jørgensen ${ }^{1}$, L. Dreyer ${ }^{1}$, B. Guőbjörnsson ${ }^{2}$, M.L. Hetland ${ }^{1}$, B. Glintborg ${ }^{1}$ J. Askling ${ }^{3}, K$. Chatzidionysiou ${ }^{3}$, D. Di Giuseppe ${ }^{3}$, L. Jacobsson ${ }^{3}$,

J.K. Wallman ${ }^{3}$, E.K. Kristianslund ${ }^{4}$, I.C. Olsen ${ }^{4}$, K. Fagerli ${ }^{4}$, E. Lie $^{4}$

D. Nordström ${ }^{5}$, K. Aaltonen ${ }^{5}$, J. Joensuu ${ }^{5}$, T.J. Love ${ }^{2}$, A.J. Geirsson ${ }^{2}$,

L.E. Kristensen ${ }^{1} .{ }^{1}$ On behalf of the DANBIO registry, Copenhagen, Denmark;

${ }^{2}$ On behalf of the ICEBIO registry, Reykjavik, Iceland; ${ }^{3}$ On behalf of the $S R Q$ registry, Stockholm, Sweden; ${ }^{4}$ On behalf of the NOR-DMARD registry, Oslo, Norway; ${ }^{5}$ On behalf of the ROB-FIN registry, Helsinki, Finland

Background: Psoriatic arthritis (PsA) is a chronic inflammatory disorder associated with skin and joint manifestations, several extra-articular symptoms, various comorbidities, and disability. The emergence of tumour necrosis factor inhibitor (TNFi) therapy has dramatically changed the course of disease. Over the past decade new TNFi therapies have emerged (certolizumab pegol and golimumab), and recently ustekinumab and secukinumab have also become available for PsA. Objectives: The objective of this study was to assess the relative use of biological agents (bDMARDs) in PsA from 2006 through 2014, using data from the Nordic Rheumatology registers.

Methods: Based on data from the observational registers DANBIO, ICEBIO, NOR-DMARD, ROB-FIN, and SRQ registers, PsA patients initiating treatment with bDMARDs as a first or subsequent biological therapy were identified. Adalimumab, etanercept and infliximab were grouped as "first generation TNFi therapies"; certolizumab pegol and golimumab were grouped as "second generation TNFi", Treatments with ustekinumab during the study period were also identified. Descriptive statistics for prescription patterns of bDMARD therapy were calculated.

Results: A total of 11,458 treatment initiations were identified (DANBIO 3,068, ICEBIO 357, NOR-DMARD 1,113, ROB-FIN 708, SRQ 6,212). 54\% of the patients were female. Overall, 5,695 patients initiated a first generation TNFi, 912 a second generation $\mathrm{TNFi}$, and 16 ustekinumab, as their first course of biological treatment. The corresponding numbers for those initiating a second (or more) biological treatment were 3,606, 1,090 and 139 patients, respectively. The figure displays the annual number of treatment initiations stratified by treatment type. The total yearly number of first course biological treatment increased significantly throughout the period $(p<0.001)$, and this was also the case for patients switching therapy $(p<0.001)$, indicating a previously unmet need for biological therapies in the Nordic population. The annual number of patients initiating first generation TNFi both as first and subsequent course of therapy decreased significantly towards the end of the study period $(p<0.001)$. This drop was more than offset by a rapid increase in initiation of second generation TNFi treatments $(p<0.001)$. Ustekinumab was primarily used as second or subsequent course of therapy in PsA. The same pattern was seen when stratified for country (data not shown).

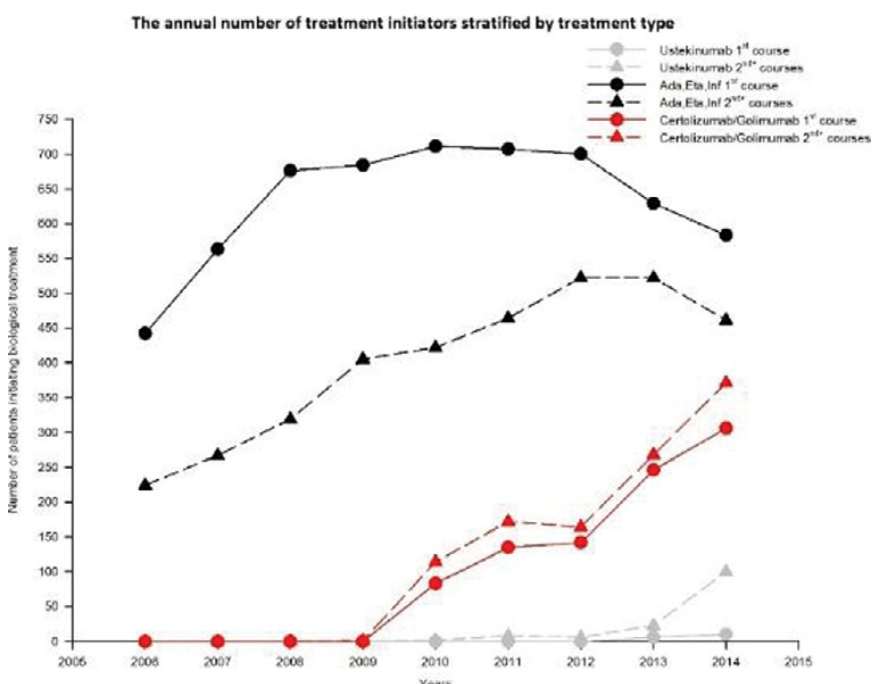

Conclusions: Across the Nordic countries the prescription pattern for biological therapies for PsA has changed significantly over time. After 2012 initiation of the first generation TNFi is decreasing both as first and second course therapy, whereas second generation TNFi are increasing both as first and second course of biologic intervention. Collaboration across registers will allow for robust assessment of the uptake of newer biological therapies.

Acknowledgements: This study was partly funded by a grant from NordForsk and Janssen Pharmaceuticals.

Disclosure of Interest: T. S. Jørgensen Speakers bureau: Abbvie, Roche, Novartis, UCB, Biogen, L. Dreyer Speakers bureau: MSD, UCB and Janssen Pharmaceuticals, B. Guőbjörnsson Speakers bureau: Actavis, Celgene, MSD, Pfizer, M. Hetland Speakers bureau: BMS, MSD, AbbVie, Roche, Eli Lilly, Pfizer, Orion, Novartis, B. Glintborg Speakers bureau: Abbvie, J. Askling Grant/research support from: AstraZeneca, UCB, Lilly, Pfizer, Roche, Merck,Samsung, Janssen, K. Chatzidionysiou Speakers bureau: AbbVie, Pfizer, Eli Lilly, UCB, Roche., D. Di Giuseppe: None declared, L. Jacobsson Consultant for: Abbvie, Celegen, MSD, Novartis and UCB, J. Wallman Consultant for: Novartis, Celgene, UCB, E. Kristianslund: None declared, I. Olsen: None declared, K. Fagerli: None declared, E. Lie Speakers bureau: AbbVie, Celgene, Hospira and Pfizer., D. Nordström Speakers bureau: AbbVie, BMS, Lilly, MSD, Novartis, Pfizer, Roche, UCB., K. Aaltonen: None declared, J. Joensuu Speakers bureau: Pfizer., T. J. Love: None declared, A. J. Geirsson: None declared, L. E. Kristensen Speakers bureau: Pfizer, AbbVie, Amgen, UCB, Celgene, BMS, MSD,

DOI: 10.1136/annrheumdis-2017-eular.4690

\section{FRI0519 EFFECT OF BIOLOGICS ON FATIGUE IN PSORIATIC ARTHRITIS: A SYSTEMATIC LITERATURE REVIEW WITH META-ANALYSIS}

T. Reygaerts ${ }^{1,2}$, S. Mitrovic ${ }^{1}$, B. Fautrel ${ }^{1}$, L. Gossec ${ }^{1} .{ }^{1}$ Service de Rhumatologie, Pitie-Salpétrière Hospital, Paris, France; ${ }^{2}$ Service de Rhumatologie et de Médecine Physique, Erasme Hospital, Bruxelles, Belgium

Background: Fatigue is an important aspect of disease both in rheumatoid arthritis (RA) and in psoriatic arthritis (PsA) and is of high priority for patients. In RA, a recent Cochrane meta-analysis found a small effect of biologics on fatigue (standardized mean difference, SMD, 0.43; $95 \%$ confidence interval, $\mathrm{Cl}$ : 0.38-0.49).(1) Little is known about this effect in PsA.

Objectives: To assess the effect of biologics on fatigue in PsA randomised controlled trials (RCTs) and to compare this effect with the effect in the same trials, on pain, through a systematic literature review (SLR) and meta-analysis (MA).

Methods: SLR up to January 2017 in PubMed, Embase and Cochrane trials database and in recent congress abstracts, using key words related to PsA and biologics. All RCTs in PsA of any biologic therapy, assessing fatigue (whatever the 